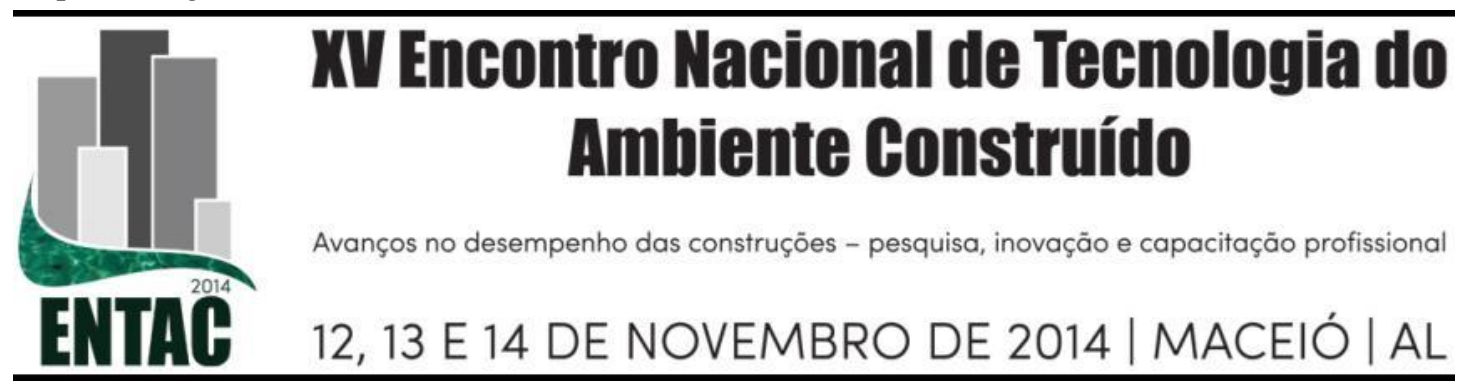

\title{
ILUMINÂNCIAS SOB A COPA DE ESPÉCIES ARBÓREAS: Medições e análises
}

\author{
LIMA, Eliana F. Costa (1); LEDER, Solange Maria (2) \\ (1) Mestranda, Programa de Pós-graduação em Engenha Civil e Ambiental - PPGECAM, Universidade \\ Federal da Paraíba (eliana_fcl@msn.com) \\ (2) Profa do Departamento de Arquitetura e Urbanismo, Universidade Federal da Paraíba \\ (solangeleder@yahoo.com.br)
}

\begin{abstract}
RESUMO
Os fatores que influenciam a disponibilidade da luz natural são diversos. Dentre eles, podemos destacar a obstrução do entorno, variável de grande impacto em áreas densamente urbanizadas. Porém, mesmo em áreas pouco urbanizadas, elementos naturais como a vegetação arbórea podem provocar uma obstrução considerável, que se traduz na alteração na quantidade de luz natural disponível no interior dos ambientes. Por outro lado, a vegetação pode proporcionar sombras e melhorar a qualidade da luz que incide através de janelas, reduzindo a intensidade da componente direta do sol, bem como o brilho vindo do céu. Sendo assim, este estudo tem como proposta verificar o comportamento da iluminação natural sob a copa de quatro espécies arbóreas : Mangueira, Pau-Brasil, Pitombeira e Carolina. O procedimento metodológico adotado consistiu no levantamento das características físicas dos tipos arbóreos escolhidos e medições in loco da iluminância. Para a obtenção dos dados de iluminância foram utilizados sensores fotométricos Li210 e dataloggers Li-1400, ambos da LI-COR. Para cada árvore foram realizados três conjuntos de medições em dias distintos, considerando três condições de céu: claro, parcialmete encoberto e encoberto. Simultaneamente ao registro das iluminâncias sob as copas das árvores, foram obtidos também os dados externos de iluminâncias, no topo do edifício mais elevado do entorno. O percentual de redução da mediana (iluminâncias), sob a copa das espécies arbóreas estudadas, foi em torno de 90 a $98 \%$ relação aos registros externos (céu encoberto, em torno de $53 \mathrm{Klux}$ ), com exceção da Pitombeira, que apresentou a menor redução em algumas orientações, em torno de 80 a $90 \%$.
\end{abstract}

Palavras-chave: Iluminação natural; Obstrução do céu; Medições de iluminação.

\begin{abstract}
Different factors impacts the daylight availability. In urban areas the sky obstruction is a considerably variable. Even in urban areas, natural elements such as vegetation can cause obstruction, which decreases the amount of available daylight. Otherwise, the vegetation can provide shadows and improve the quality of light, reducing the light intensity from the sun and the sky. This study investigates the impacts of vegetation on illuminance levels under the canopy of four species: Mangifera indica, Caesalpinia echinata, Talisia esculenta and Adenanthera pavonina. The physical characteristics of canopy were measured and measurements of illuminance were collected. To obtain the photometric data illuminance sensors and dataloggers $210 \mathrm{Li}-\mathrm{Li}-1400$, both from LI-COR were used. Daylight measurements were taken on different days, considering three sky conditions: clear, partly cloudy and overcast. Data from the external illuminance, at the top of the highest building, were also taken. The median illuminance reduction, under the canopy, was around 90-98\%, compared to external data (overcast sky, around 53 Klux), except the Pitombeira, which had the lowest reduction, around 80-90\%.
\end{abstract}

Keywords: Daylighting; Sky obstruction; Daylight measurements. 


\section{INTRODUÇÃO}

Os fatores que influenciam a disponibilidade da luz natural são diversos. Dentre eles, podemos destacar a obstrução do entorno, variável de grande impacto em áreas densamente urbanizadas. O planejamento da luz natural exige atenção especial ao efeito das obstruções circunvizinhas, mesmo em áreas pouco urbanizadas, elementos naturais como a vegetação arbórea podem provocar uma obstrução considerável, que se traduz na alteração na quantidade de luz natural disponível no interior dos ambientes (HOPKINSON et al., 1975).

A arborização inserida no meio urbano pode oferecer proteção solar para os edifícios, reduzindo o consumo de energia para o condicionamento térmico interior devido à sua sombra, influenciando nas trocas de calor e provocando diminuição das temperaturas (VILLALBA et al., 2014). No estudo de Donovan e Butry (2009) o sombreamento proveniente do entorno arborizado resultou em uma redução em torno de 5\% no consumo de energia elétrica com ar-condicionado. Givoni (1992) afirma ainda que as árvores contribuem para a melhoria do microclima imediato, citando o aspecto térmico como o maior benefício. Quanto maior a densidade das mesmas, maior a ação na filtragem do ar, na promoção da privacidade e no sombreamento e no controle do iluminamento excessivo do sol. Nos climas quentes, as superfícies vegetadas e as folhas das árvores absorvem a radiação solar, o sombreamento reduz as temperaturas superficiais e, o processo de evapotranspiração diminui a temperatura do ar.

\section{OBJETIVO GERAL}

Verificar o comportamento da iluminação natural sob a copa de quatro espécies arbóreas amplamente cultivadas na cidade de João Pessoa: Mangueira, Pau-Brasil, Pitombeira e Carolina.

\section{O EFEITO DA VEGETAÇÃO SOBRE A ILUMINAÇÃO}

O bloqueio da luz solar direta, principalmente em clima quente, favorece o uso da luz natural nos ambientes internos. As plantas podem proporcionar sombras e melhorar a qualidade da luz que incide através de janelas, reduzindo a intensidade da componnente direta do sol, bem como o brilho vindo do céu (AL-SALLAL, 2009). A luz solar que atravessa as aberturas pode ser filtrada e suavizada pela presença de vegetação ou elementos de proteção solar, como venezianas, cortinas, entre outros. Segundo Mascaró (2010), o sombreamento da vegetação tem grande influência sobre a luz natural nos recintos urbanos e, consequentemente, afeta o desempenho da luz natural nas edificações. A forma da copa das árvores e seu tamanho determinam a área sombreada, que muda de acordo com a espécie e com a época do ano. Uma escolha adequada deve levar em consideração as mudanças de forma e tamanho que se processarão ao longo do tempo, baseada nas condições de insolação do recinto urbano através do ano e das necessidades de sombreamento em cada estação. Neste sentido, Chen (2006) e Piveta (2010) concluíram que a influência da vegetação nas condições ambientais internas de edificações relaciona-se diretamente com o Índice de Área Foliar (IAF). Segundo Watson (1947), o Índice de Área Foliar (IAF) é a área foliar integrada do dossel por unidade de superfície projetada no solo, uma variável adimensional $\left(\mathrm{m}^{2}\right.$ folha $/ \mathrm{m}^{2}$ de solo). Este índice está relacionado com a quantidade de luz interceptada pela copa e tem influência direta nas temperaturas superficiais das áreas sombreadas (CHARLES EDWARDS e THORNLEY, 1972). Copas densas possuem IAF elevado, portanto, transmitem menor quantidade de luz sob a copa. 
No estudo realizado por All-Sallal (2009) evidenciou-se a importância da sombra de árvores na melhoria da qualidade e distribuição da iluminação natural. $\mathrm{O}$ autor investigou a influência das espécies Neem e Ghaf nas condições de iluminação de salas de aulas, através de simulação computacional. A referida pesquisa concentrou-se na análise da iluminância que incide no plano de tarefa de salas de aula voltadas para norte, sul, leste e oeste, a fim de identificar os momentos críticos que são relevantes para a localidade. A vegetação é um elemento de difícil inserção no projeto da iluminação natural, considerando, por exemplo, a simulação computacional, todos os elementos intervenientes na reprodução da luz devem ser modelados tridimensionalmente. Contudo, essa modelagem é impraticável, não somente devido à complexidade de todas as variáveis relatadas, como também, na sobrecarga do modelo. No entanto, alguns métodos de caracterização da vegetação, podem ser introduzidos para simplificar a sua reprodução e modelagem. Neste contexto, medições in loco da iluminação sob a copa de árvores contribuem para a caracterização de tipos arbóreos. Al-Sallal (2013) também desenvolveu um método, a partir de fotografias hemisféricas, para a construção simplificada de um modelo tridimensional de copa de árvore em ambiente digital (simulação da luz natural). O modelo 3D de copa de árvore, resultante da aplicação do método proposto, foi usado para simular o efeito da interceptação da luz sob espécies arbóreas. Os resultados das simulações foram validados através da comparação com medições reais de iluminância realizadas em campo, com expressiva concordância entre os níveis de iluminância simulados e medidos.

\section{MATERIAIS E MÉTODO}

A metodologia utilizada para este estudo divide-se em três etapas: seleção e levantamento das árvores, medições da iluminância sob a copa das árvores e análise dos resultados, detalhadas nos tópicos a seguir.

\subsection{Seleção e levantamento das árvores}

Os tipos arbóreos utilizados nesta pesquisa foram selecionados a partir das espécies existentes no Campus I da Universidade Federal da Paraíba - UFPB, na cidade de João Pessoa-PB. A escolha por esta área se deu em função da existência de grande diversidade de espécies e da proximidade com o local de estudo, facilitando e diminuindo o tempo de deslocamento com equipamentos. Todas as árvores selecionadas estão inseridas no Centro de Tecnologia da UFPB, ver indicação na Figura 1 abaixo.

Figura 1 - Localização da área de estudo

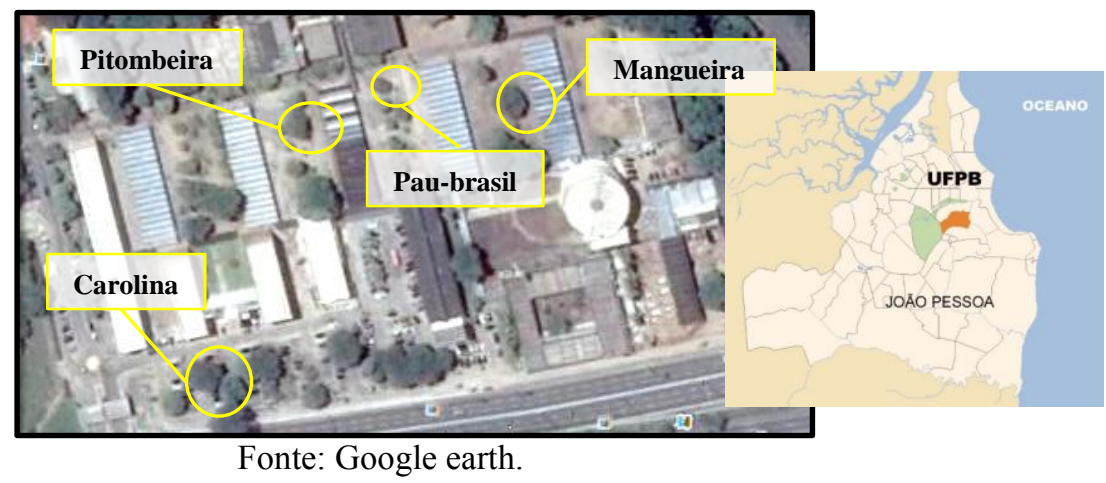


Para seleção das espécies arbóreas, considerou-se alguns aspectos: espécies recorrentes na cidade de João Pessoa; dimensão com portes diferenciados (grande, médio e pequeno); copas regulares, ausência de podas radicais; folhas com tamanhos e composições diferenciadas; e entorno, onde a condicionante foi uma situação em que a árvore se encontrasse com o máximo de afastada de elementos naturais e edificados, objetivando a redução da componente refletida da luz natural.

Na Figura 2 pode-se visualizar a implantação das árvores na área do Centro de Tecnologia da UFPB. As espécies denominadas de 01, 02 e 03 estão localizadas em vãos existentes entre os blocos $\mathrm{D}, \mathrm{F}, \mathrm{G}$ e $\mathrm{H}$, edificações térreas. A espécie 04 está localizada no estacionamento, próxima ao bloco de aulas CTJ, que possui 3 pavimentos.

O levantamento da vegetação em estudo foi realizado in loco com auxílio de trena comum. Cada tipo teve a largura e o comprimento da copa medido, posteriormente, através de fotografias, foram calculadas as dimensões verticais da copa, como também altura total da árvore. Paralelamente ao levantamento geométrico, obtiveram-se também, tendo com base comparativa a cartela de cores da CIBSE (2001), os valores de refletância das folhas e da entorno no qual cada árvore está inserida.

Figura 2 - Identificação dos tipos arbóreos

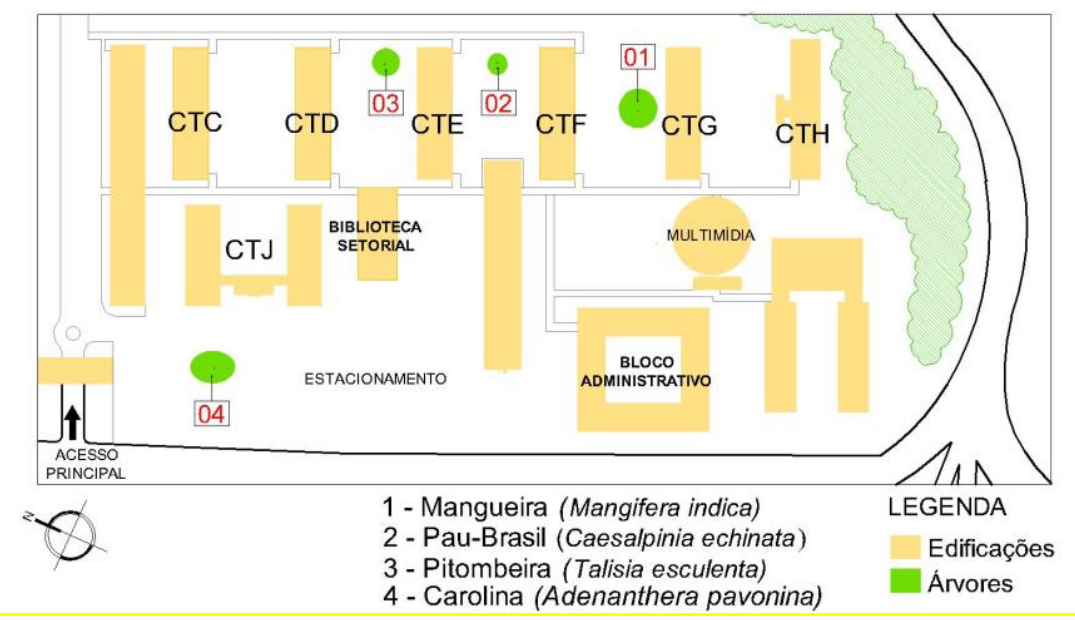

\subsection{Medições da iluminância}

As medições das iluminâncias, sob a copa das 04 espécies arbóreas em análise, ocorreram no período de 10 de junho de 2013 à 30 de julho de 2013, no horário das 11:00 às 13:00h. Este horário foi estabelecido considerando a sombra da árvore, projetada ortogonalmente sobre o piso. Oito pontos de medição foram locados, com os sensores fotométricos apoiados em tripés, com as medições ocorrendo a cada 1 minuto. Para a armazenagem dos dados foi utilizado um conjunto de três dataloggers. Os pontos, localizados a 1,5 metros do centro da copa (tronco da árvore) e a uma altura de 1,5 metros a partir do solo, foram posicionados conforme a orientação norte, sul, leste, oeste, nordeste, noroeste, sudeste e sudoeste (Figuras 3 e 4). Para o nivelamento dos sensores foi utilizado o kit de fixação da Li-cor que contém um nível de bolha.

Para cada árvore foram realizados três conjuntos de medições em dias distintos, considerando três condições de céu predominante: claro, parcialmente encoberto e encoberto. Simultaneamente aos registros das iluminâncias sob as copas das árvores, foram obtidos também os dados externos de iluminâncias, a uma altura de aproximadamente 12 metros (cobertura do edifício mais elevado do local), objetivando 
o máximo de desobstrução do entorno, utilizando sensores e datataloggers LI-COR (Li210 e Li 1400.

Figura 3 - Detalhe do sensor e tripé (a); Sensores sob a copa da árvore (b)
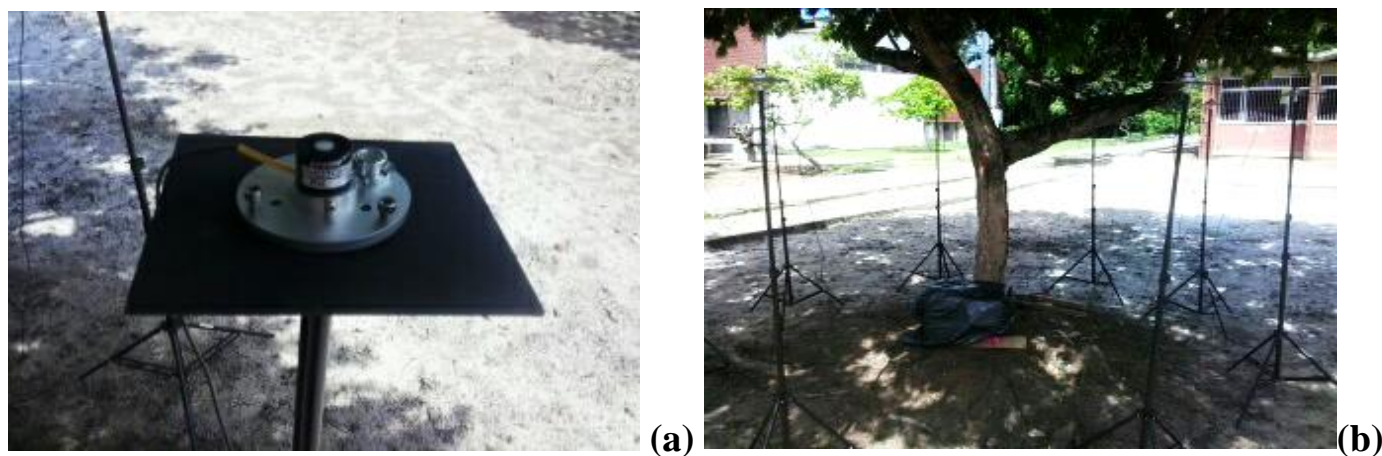

Figura 4 - Planta e corte da locação dos sensores sob a copa das árvores

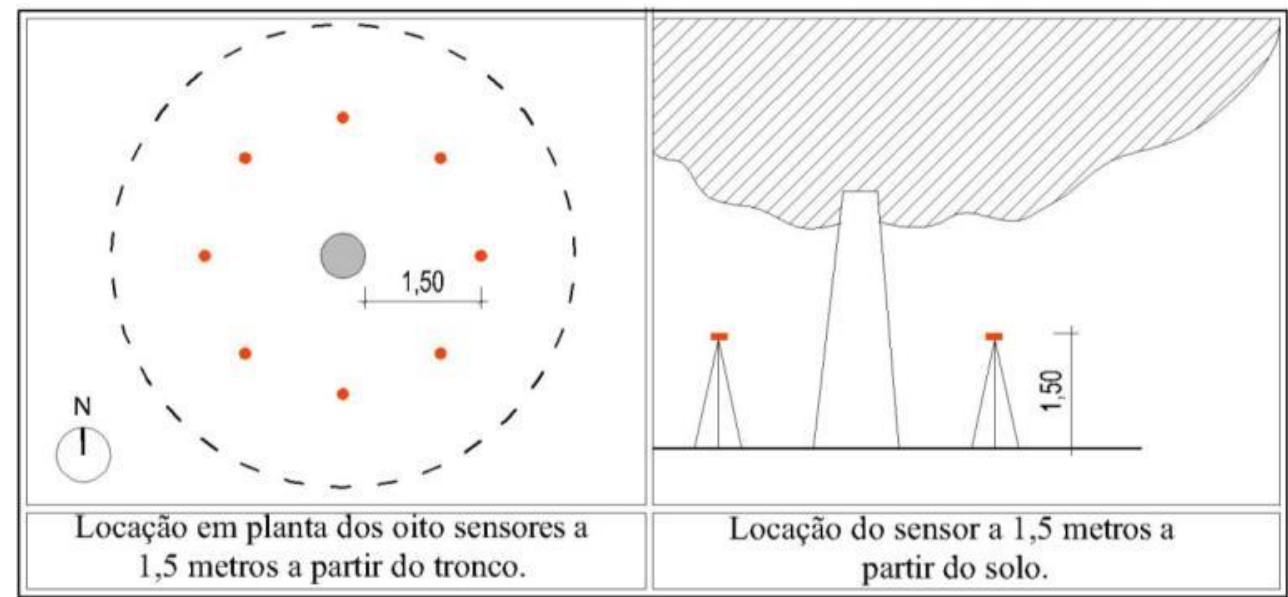

\section{RESULTADOS E DISCUSSÃO}

Os resultados, apresentados a seguir, referem-se à caracterização da copa das árvores e às medições das iluminâncias sob as mesmas.

\subsection{Caracterização da copa das espécies arbóreas em análise}

As principais características dos tipos arbóreos em estudo estão apresentadas no Quadro 1. A refletância do piso no qual a Mangueira e o Pau-Brasil estão implantados, sob a luz solar direta é de 26, na sombra o valor encontrado corresponde a 13. Para o piso no entorno da Pitombeira e da Carolina, sob luz solar direta, o valor identificado foi de 28 , na sombra a refletância é de 16. A refletância das folhas está apresentada no Quadro 1, os valores estão em torno de 13 e 16.

A Mangueira e a Carolina, em estudo, são árvores de grande porte. A Mangueira apresentando copa fechada, arredondada e simétrica, já a Carolina, apresenta ramagem longa e esparsa, formando uma copa aberta. O pau-brasil apresenta um porte pequeno e a copa levemente irregular. A Pitombeira apresenta porte médio e copa aberta (observar imagens do Quadro 1). 


\section{Quadro 1 - Características geométricas das espécies arbóreas em estudo}

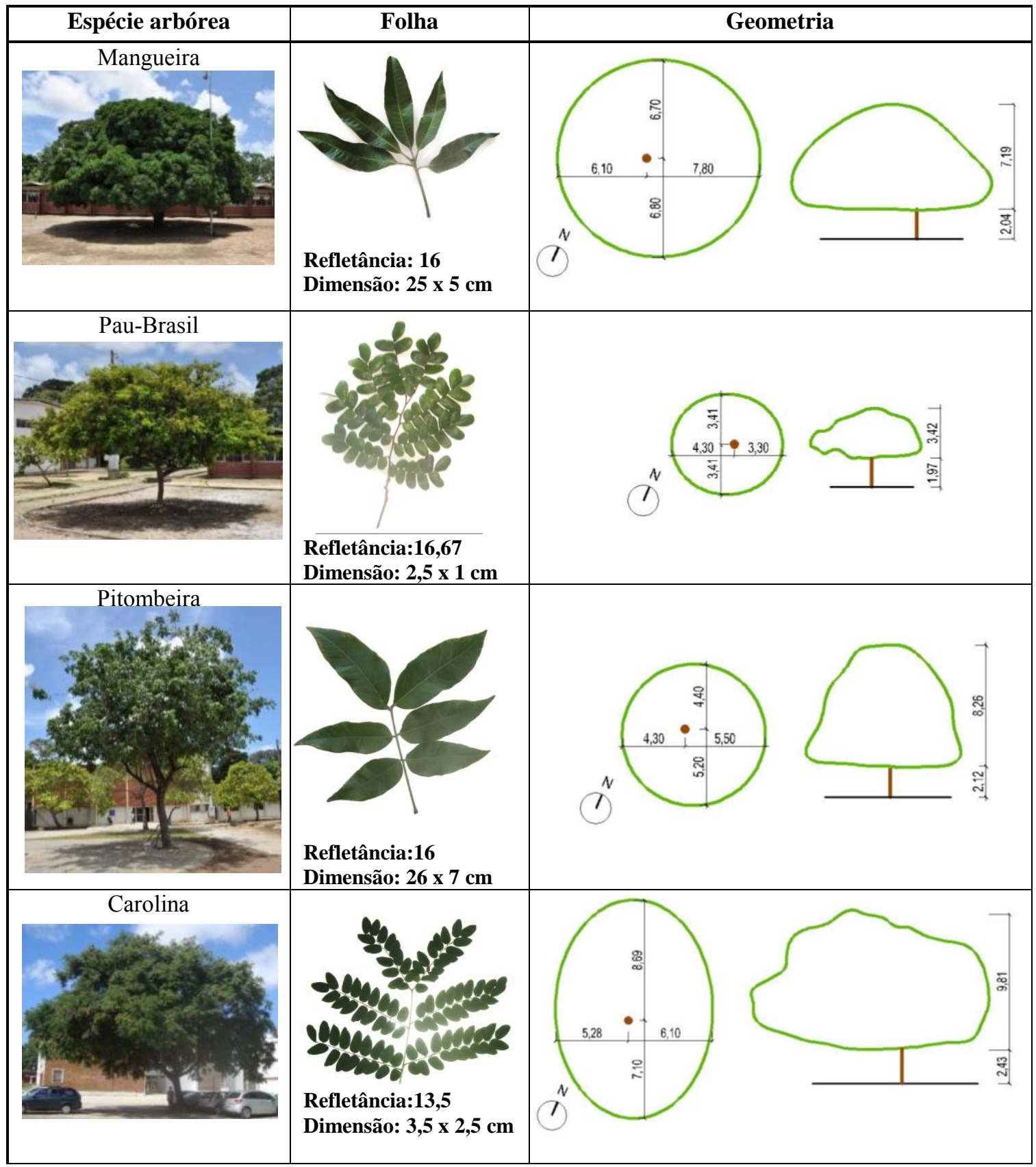

\subsection{Medições das iluminâncias}

Os dados provenientes das medições de iluminância, realizadas sob a copa das 4 espécies de árvore escolhidas para este estudo e na condição de entorno desobstruído, podem ser visualizados nos gráficos das Figuras 5 a 11.

A Figura 5 representa as iluminâncias (Klux) registradas na cobertura do edifício, caracterizando uma condição de céu desobstruído. Com céu claro a iluminância mínima ficou em torno de $75 \mathrm{Klux}$, a máxima em torno de 110 Klux e $50 \%$ das iluminâncias estão concentradas entre 94 e 102 Klux. Para os dias parcialmente encobertos, a iluminância mínima foi de $45 \mathrm{Klux}$, a máxima em torno de $95 \mathrm{Klux}$, com 50\% das iluminâncias concentradas entre 73 e 84 Klux. Nos dias encobertos, a iluminância mínima está em torno de $30 \mathrm{Klux}$, a máxima de $75 \mathrm{Klux}$, estando 50\% das iluminâncias 
agrupadas entre 42 e 56 Klux. Nos dias de céu claro a maior frequência ocorreu entre 95 e 100 Klux, nos dias de céu parcialmente encoberto, a maior frequência esteve entre 70 e 75 Klux e, nos dias de céu encoberto, a maior frequência ficou entre 40 e 45 Klux.

Figura 5 - Iluminâncias: céu claro, parcialmente encoberto e encoberto

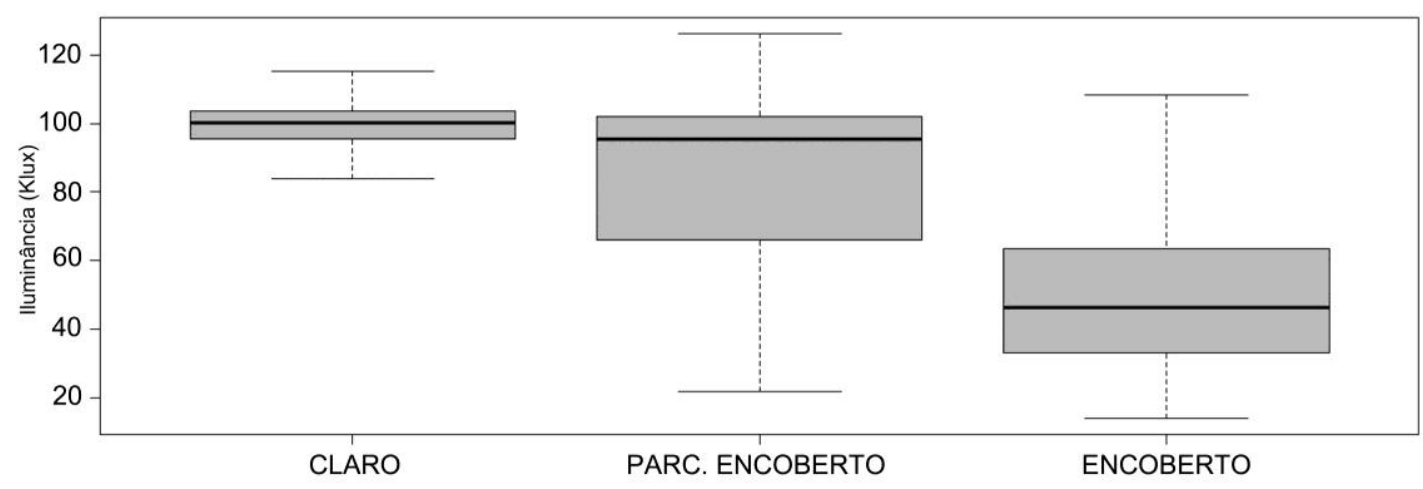

Na figura 6 observam-se os resultados das medições para a mangueira. A orientação norte apresentou os menores valores em Klux e a menor variação. Já as orientações Sul, Leste e Sudoeste apresentaram os maiores níveis e também as maiores variações. Atribui-se essas diferenças à geometria da copa e à reflexão do entorno. Em relação à geometria da copa, o tronco, tomado como referência para a distribuição dos sensores, não se encontra no centro da mesma, consequentemente a sombra no lado sul é menor. Além disso, $\mathrm{Na}$ orientação leste há uma considerável lacuna na ramagem da copa. As medianas da iluminância estão entre 1,58 e 3,75 (Klux), que representa uma redução média de 95,34\% em relação às iluminâncias medidas na condição de céu desobstruído.

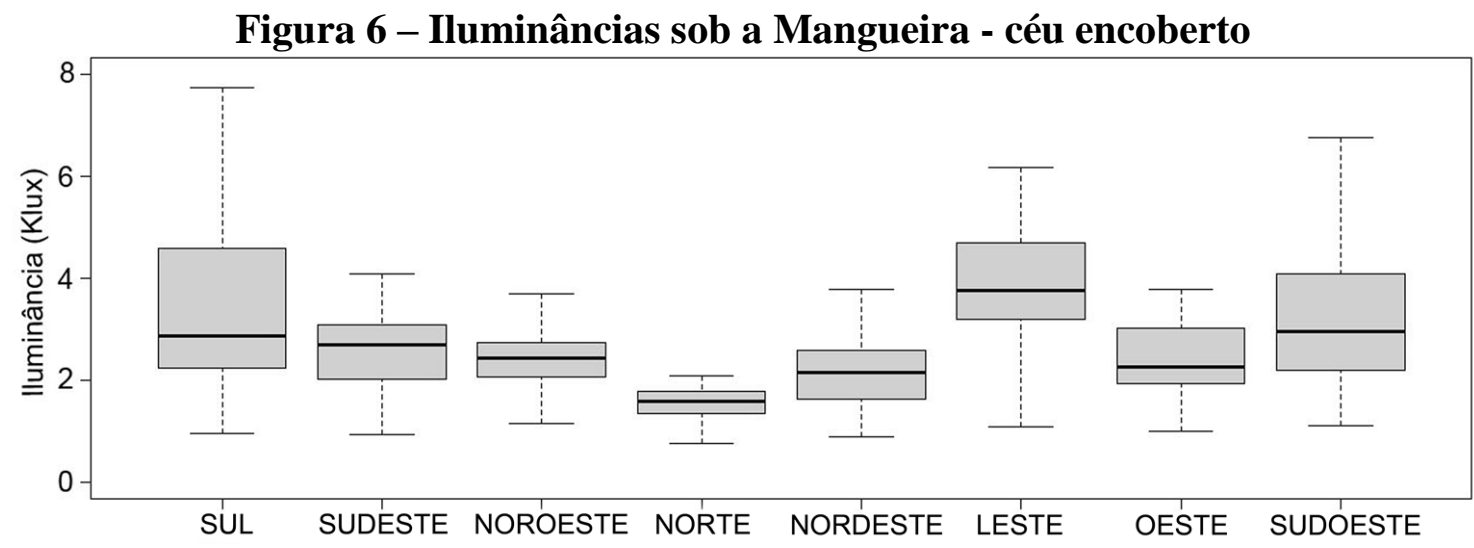

Figura 7 - Iluminâncias sob o Pau-Brasil - céu encoberto

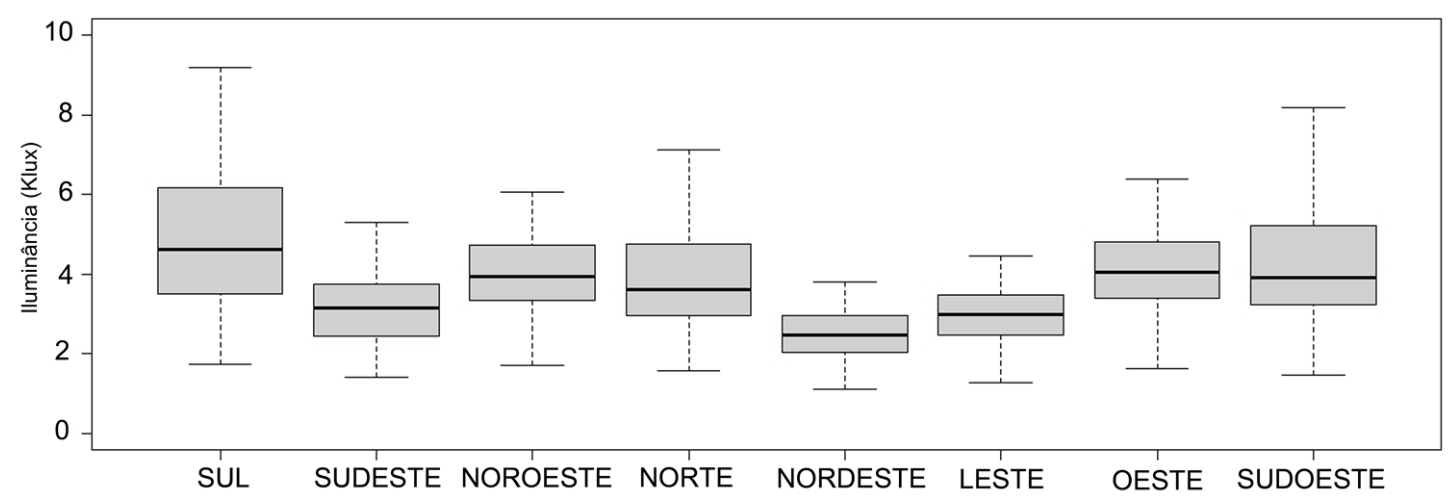


Na Figura 7 encontram-se as iluminâncias sob a copa da árvore 02 (Pau-Brasil). As medianas das iluminâncias apresentam-se entre 2,48 Klux (nordeste) e 4,61 Klux (sul), representando redução de aproximadamente $93,10 \%$ em relação à condição de céu desobstruído. Observa-se maior variação e amplitude dos valores de iluminância nas orientações sul, sudoeste e norte. Atribui-se essas diferenças, da mesma forma que a mangueira, à refletância do entorno e à geometria da copa, principalmente porque o tronco, tomado como referência para a distribuição dos sensores, não se encontra no centro da copa.

As medições de iluminância sob a árvore 03 (Pitombeira) estão na Figura 8. Observa-se medianas entre 2,49 Klux (leste) e 6,22 Klux (sudoeste) que representa um percentual de redução de aproximadamente $88,47 \%$. Observa-se que, a variação da iluminância ocorreu de forma mais constante entre as orientações, caracterizando uma copa com distribuição de lacuna mais homogênea. Desta forma, atribui-se os níveis de dispersão mais elevados, ocorridos nas orientações sul, sudoeste, oeste e norte, à refletância do entorno

Figura 8 - Iluminâncias sob a Pitombeira - céu encoberto

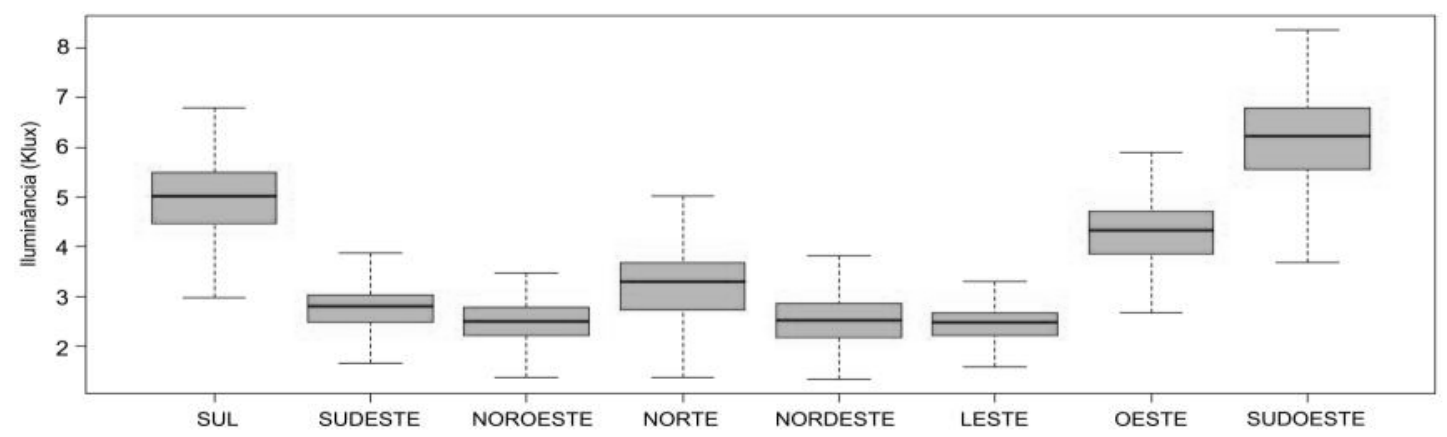

Na Figura 9 observa-se os resultados das medições para a Carolina. As medianas apresentam-se entre 2,18 Klux (norte) e 3,12 Klux (sul), correspondendo a um percentual de redução de cerca de $94,79 \%$. Os níveis de dispersão da iluminância e as variações mostram-se mais constantes em relação as demais árvores. Neste caso, podese associar os baixos níveis e a constância da iluminância à geometria (grandes dimensões) e a alta densidade da copa da Carolina juntamente com o tipo de folha, o que possibilita a permeabilidade da luz de forma mais constante e melhor distribuída.

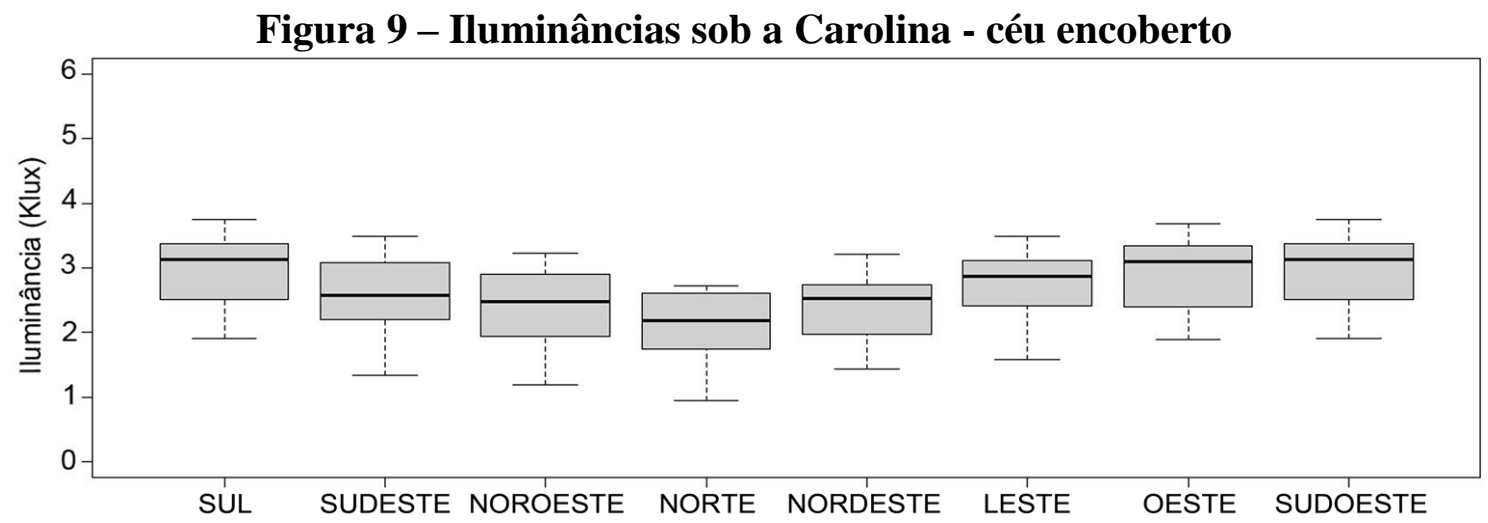

Na Figura 10 as iluminâncias estão agrupadas conforme a árvore analisada, enquanto na Figura 11 observa-se o percentual de redução das medianas, observadas em cada árvore 
e orientação, em relação à iluminância na condição de céu desobstruído. Nota-se que sob o Pau-Brasil, a Pitombeira e a Carolina a mediana variou entre 2800 e 2900 Lux. A mangueira apresentou a mediana mais baixa, aproximadamente 1600 Lux. As medianas oscilam entre 92 e 96\%, para a Mangueira, Pau-Brasil e Carolina. A Pitombeira apresentou menores reduções, em torno de $90 \%$ e $92 \%$, bem como a menor redução, de $80 \%$. A menor variação das iluminâncias ocorreu sob a copa da Carolina, estando $50 \%$ das iluminâncias concentradas entre 2,5 e 3,2 Klux.

Figura 10 - Iluminâncias sob a copa das espécies em análise

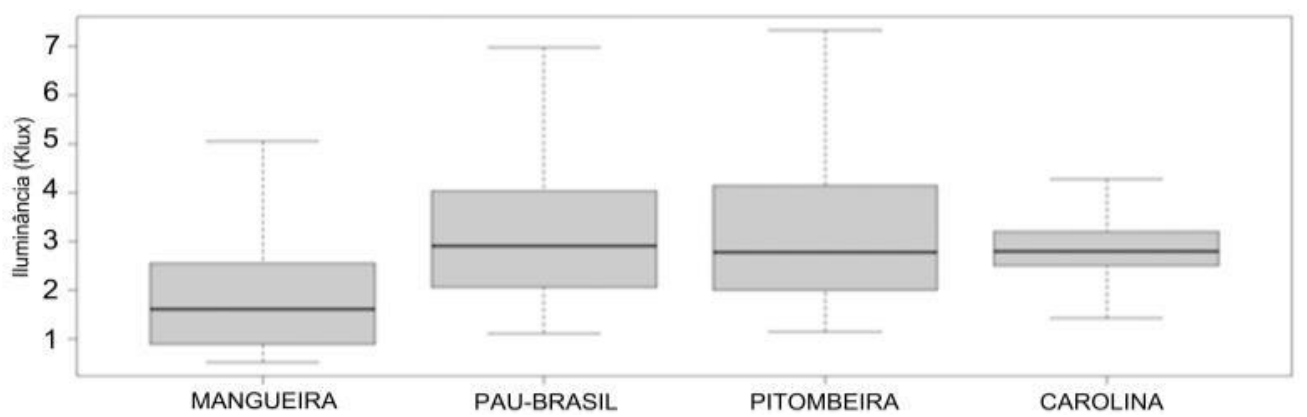

Figura 11 - Percentual de redução da mediana

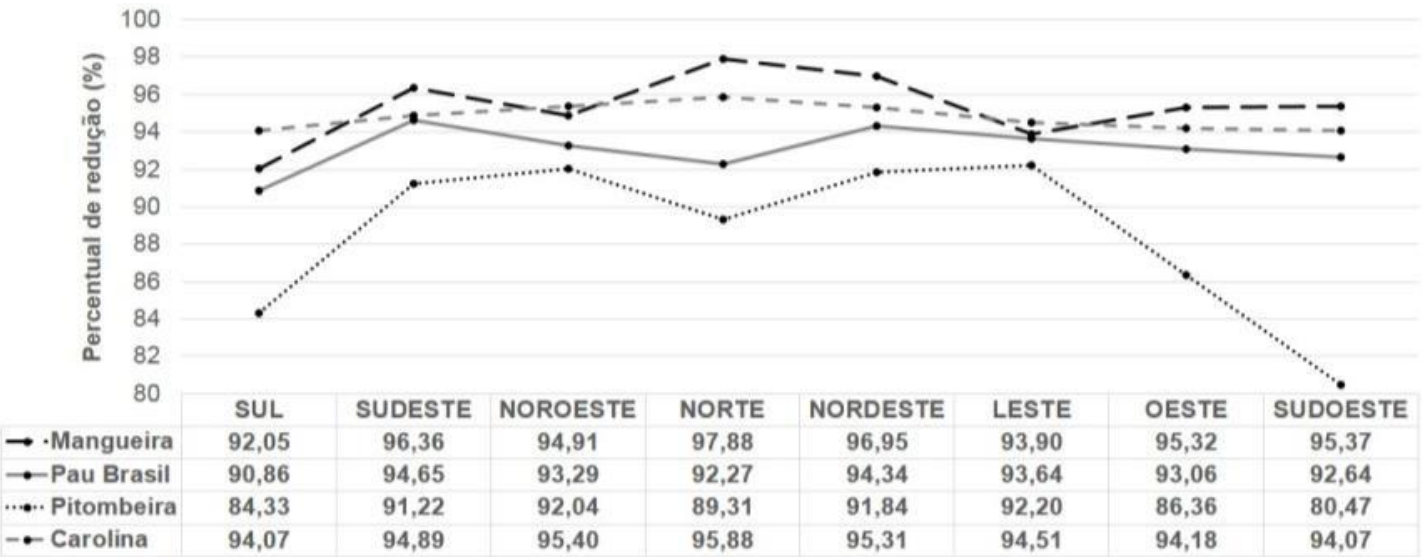

A mangueira possui copa densa e folhas relativamente grandes (comparando-se com as demais árvores em análise), proporcionando menor quantidade de lacuna entre as folhas, consequentemente menos luz é transmitida para baixo da copa. A Carolina também possui copa densa, porém suas folhas são compostas por pequenos folíolos resultando em menor variação da luz sob a copa.

\section{CONSIDERAÇÕES FINAIS}

Através de medições in loco, este trabalho verificou as iluminâncias sob a copa de quatro espécies arbóreas: Mangueira, Pau-Brasil, Pitombeira e Carolina. As maiores amplitudes da iluminância foram observadas no Pau Brasil e na Pitombeira, cujas copas são abertas e pouco densas, possuindo consideráveis lacunas entre as folhas.

Observa-se que, o Pau-brasil, a Pitombeira e a Carolina apresentaram medianas aproximadamente iguais, porém a variação da iluminância sob a copa da Carolina foi consideravelmente menor. Isto pode estar relacionado à fatores, tais como: densidade e dimensão da copa, tipo de folha, bem como a refletância do entorno. A mangueira apresentou os menores níveis de dispersão, porém com variação, relativamente próxima 
à do Pau-brasil e Pitombeira. Apesar da mangueira ser uma árvore de copa densa e folha grande, esta variação da iluminância pode ser explicada pela presença de vazios inconstantes na ramagem da copa, permitindo consideráveis variações na penetração da luz, além da contribuição do entorno.

O percentual de redução da iluminâncias sob a copa das espécies arbóreas estudadas, variou entre $90 \%$ à 98\% em relação aos registros externos (aproximadamente 53 Klux), com exceção da Pitombeira, que apresentou a menor redução em algumas orientações, em torno de $80 \%$ à $90 \%$. As orientações sul e sudoeste foram as que apresentaram as maiores amplitudes e variações de iluminância em todas as espécies estudadas, esse diferencial foi atribuído à geometria da copa e às reflexões do entorno.

\section{AGRADECIMENTOS}

Ao $\mathrm{CNPq}$ e à CAPES, pelo apoio recebido.

\section{REFERÊNCIAS}

AL-SALLAL, Khaled A. AL-RAIS, Laila. A novel method to model trees for building daylighting simulation using hemispherical photography. Journal of Building Performance Simulation, Emirados Árabes, v.6, n.1, p. 38-52, Janeiro 2013.

AL-SALLAL, K.A., ABU-OBEID, N. Effects of shade trees on illuminance in classrooms in the United Arab Emirates. Architectural Science Review, Emirados Árabes, v. 52, n. 4, p. 295-311, 2009.

AL-SALLAL, K.A Practical method to model trees for daylighting simulation using hemispherical photography. Building Simulation: Eleventh International IBPSA Conference. 2009.

CHEN, Y. The intervention of plants in the conflicts between buildings and climate - $\mathrm{A}$ case study in Singapore. 2006. 336f. Thesis (Doctor in Philosophy). Department of Building, National University of Singapore, Singapore.

CHARLES-EDWARDS, D. A.; THORNLEY, J. H. M. Light Interception by an Isolated Plant: A Simple Model. Lilllehampttin, Sussex Received: 6, 1972.

DONOVAN, G. H.; BUTRY, D. T. The value of shade: Estimating the effect of urban trees on summertime electricity use. Energy and Buildings. London: Elsevier, v.41, p. 662-668, 2009.

GIVONI, B. Comfort Climate Analysis and Building Design Guidelines. Energy and Buildings, v. 18, n. 1, 1992.

HOPKKINSON, R.G.; PETHERBRIDGE, P.; LONGMORE, J. Iluminação Natural. Lisboa: Fundação Calouste Gulbenkian, 1975. 776p.

MASCARO, Juan L.; MASCARO, Lucia E. A. R. Vegetação Urbana. 3. ed. Porto Alegre: maisquatro, 2010.

PIVETA, Joseane. Influência de elementos paisagísticos no desempenho térmico de edificação térrea. 2010. 69 f. Dissertação (Mestrado em Engenharia de Edificações e Saneamento) - Universidade Estadual de Londrina, Londrina, 2010.

VILLALBA, A.; PATTINI, A.; CORREA E. An approach to urban tree daylight permeability simulation using models based on louvers. Building and Environment. Mendonza, V. 73, p. 75-87, fev. 2014.

WATSON, D. J. Comparative physiological studies on growth of field crops: I.Variation in net assimilation rate and leaf area between species and varieties, andwithin and between years. Annals of Botany, v. 11, p. 41-76. 1947. 